University of Nebraska - Lincoln

DigitalCommons@University of Nebraska - Lincoln

Faculty Publications: Department of Entomology

2004

Sunflower Beetle (Coleoptera: Chrysomelidae): Pattern of Larval Distribution and Parasitism in Cultivated Sunflower Fields

Gary J. Brewer

University of Nebraska-Lincoln, gbrewer2@unl.edu

Laurence D. Charlet

USDA, ARS, Northern Crop Science Laboratory

Follow this and additional works at: https://digitalcommons.unl.edu/entomologyfacpub

Part of the Entomology Commons

Brewer, Gary J. and Charlet, Laurence D., "Sunflower Beetle (Coleoptera: Chrysomelidae): Pattern of Larval Distribution and Parasitism in Cultivated Sunflower Fields" (2004). Faculty Publications: Department of Entomology. 230.

https://digitalcommons.unl.edu/entomologyfacpub/230

This Article is brought to you for free and open access by the Entomology, Department of at DigitalCommons@University of Nebraska - Lincoln. It has been accepted for inclusion in Faculty Publications: Department of Entomology by an authorized administrator of DigitalCommons@University of Nebraska - Lincoln. 


\title{
Sunflower Beetle (Coleoptera: Chrysomelidae): Pattern of Larval Distribution and Parasitism in Cultivated Sunflower Fields
}

\author{
Gary J. Brewer and Laurence D. Charlet ${ }^{1}$ \\ Department of Entomology, North Dakota State University, \\ Fargo, North Dakota 58105.
}

\begin{abstract}
The sunflower beetle, Zygogramma exclamationis (Fabricius), is a major pest of commercial sunflower, Helianthus annuus L. (Asteraceae), in the Plains area of central North America. Although an economic injury level for the sunflower beetle has been determined, in-field distributions of the larvae and their natural enemies have not been described. Over a three year period, fields were sampled for sunflower beetle larvae and for larvae of the endoparasitoid, Myiopharus macellus (Reinhard). Sunflower beetle larvae were generally found to have aggregated distributions. Knowledge of the distribution pattern will allow the development of more efficient sunflower beetle sampling protocols. Parasitism rates of M. macellus throughout fields were equivalent, indicating effective host searching. Although the data supports aggregated distributions for M. macellus, it is less clear than that for the sunflower beetle.

KEY WORDS: Zygogramma exclamationis, Chrysomelidae, Myiopharus macellus, Tachinidae, endoparasitoid, distribution pattern
\end{abstract}

The sunflower beetle, Zygogramma exclamationis (Fabricius), is the most damaging defoliator of cultivated sunflower in the United States (Westdal, 1975; Rogers, 1977; Charlet et al., 1997). Leaf feeding by both the adult and larval stages of the beetle can injure the sunflower (Helianthus annuus L.) (Asteraceae) plant. Adults feed during the day and consume the sunflower foliage beginning on the leaf margins. Larvae are generally nocturnal feeders and feed over the entire surface of the leaf. During the day they congregate around the terminal portions of the plant. The sunflower beetle overwinters as an adult and emerges in late May and early June. After mating, eggs are laid on wild or volunteer sunflower until cultivated plants are available. Eggs are deposited on stems and the underside of leaves. Eggs are present in the field for about a month, beginning in early June. Larvae develop through four instars and are found from mid-June through late July. The larvae pupate in the soil and emerge as new-generation adults in late July to early August. These adults, although present on the sunflower plants, cause minimal damage, and by mid-September have left their host plants to overwinter in the soil (Charlet, 1991, 1992).

The sunflower beetle is distributed throughout the Great Plains from Manitoba to Arizona (Brisley, 1925; Westdal, 1975). However, most economic damage occurs in the northern Plains states of North Dakota, South Dakota, and Minnesota, and the Canadian province of Manitoba (Westdal, 1975; Charlet, 1992). A number of generalist predators such as coccinellids, pentatomids, and carabids limit sunflower beetle damage by feeding on both eggs and larvae (Westdal, 1975). Parasitoids also are important in limiting populations and attack all stages of the sunflower beetle. The egg and larval parasitoids, Erixestus winnemana Crawford (Hymenoptera: Pteromalidae), Myiopharus macellus (Reinhard) (Diptera: Tachinidae), and Myiopharus sp. (Tachinidae) reared from adults, are associated with the sunflower beetle (Westdal, 1975; Charlet, 1992).

The sunflower beetle is a native North American insect that has successfully transferred to the cultivated crop. To colonize commercial sunflower, the sunflower beetle has had to

\footnotetext{
${ }^{1}$ USDA, ARS, Northern Crop Science Laboratory, Box 5677, University Station, Fargo, North Dakota 58105.

Accepted 11 September 2003; revised 20 September 2003.

(C) 2004 Kansas Entomological Society
} 
adapt from natural systems of native sunflowers intermixed with other plants, to large plantings of monoculture sunflower. Although sampling protocols and economic injury levels for the sunflower beetle on commercial sunflower have been developed (Knodel et al., 2000), little is known about its distribution or the distributions of its natural enemies in monoculture. This study examined distributions of larval sunflower beetles and its larval parasitoid, M. macellus in commercial sunflower fields.

\section{Materials and Methods}

Large plots and commercial sunflower fields were sampled over a three-year period to determine sunflower beetle larvae and parasitoid numbers at different locations in fields. Sampling was timed to when the majority of eggs had hatched, larvae of all instars were present, and prior to the movement of mature larvae into the soil to pupate (Charlet, 1992). Research in that study showed that eggs are generally present for one month (June), although in one year they were detected until mid-July. At this time, most of the plants were in the early reproductive stage (R1-4) (Schneiter and Miller, 1981).

1996: Seven fields in southeastern North Dakota were sampled for sunflower beetle larvae between 26-31 July 1996. Fields included two 0.4-hectare (ha) plots and five commercial fields ranging in size from 32 to 49 ha. Attempts were made to sample each field along each side and in the center. However, because of access difficulties, two commercial fields were only sampled on three sides, and one was not sampled in the middle. When a preferred site was not accessible, an additional sample was taken elsewhere in the field so that all fields were sampled at five sites. Twenty plants were sampled at each site. All larvae per plant were counted by instar and plant stage was recorded. No samples were taken directly on the field margins.

1997: Five commercial fields were sampled on 22 and 23 July 1997 to determine the distribution of sunflower beetle larvae. The approximately rectangular-shaped fields ranged in size from 13 to 194 ha and were located in southeastern North Dakota. Transects into each field were located one per field side and larvae were sampled at the field margin and at 20,50, and $100 \mathrm{~m}$ along the transect. Larvae of the sunflower beetle were counted on 10 randomly selected plants at each sampling site. To calculate the percentage of larvae parasitized by the tachinid, M. macellus, 50 sunflower beetle larvae were collected per sampling site and dissected in the laboratory. Comparisons of dissected parasitoid larvae were made with previously identified parasitoids specimens mounted on microscope slides (Charlet, 2003).

1998: Five commercial fields in southeastern North Dakota were sampled on 21 and 23 July in 1998 for sunflower beetle larval parasitoids as in 1997. Fifty sunflower beetle larvae were randomly collected on sunflower plants from the north, east, south, and west sides of each field at the edge and at 20,40, and $60 \mathrm{~m}$ into the field. The larvae were brought to the laboratory and dissected to determine percentage parasitized by $M$. macellus.

DATA ANALYSIS: Analysis of variance (PROC GLM; SAS System for Windows, 8.02) (SAS, 1989) was used to compare population densities at different locations in fields. ENSTAT, an ecological analysis program (Pedigo and Zeiss, 1996), was used to test fit of populations to Poisson and negative binomial distributions.

\section{Results}

LARVAL DISTRIBUTION 1996: Although the numbers of larvae per plant differed significantly $(F=2.52, P<0.0401$, d.f. $=4,695)$ per location in the field, the range was small, varying 
Table 1. Dispersion parameters of sunflower beetle larvae in hybrid sunflower fields in North Dakota, 1996, 1997.

\begin{tabular}{|c|c|c|c|c|c|c|c|}
\hline \multicolumn{2}{|c|}{ Sampling } & \multirow{2}{*}{$\begin{array}{c}\text { Field } \\
\text { location }\end{array}$} & \multicolumn{2}{|c|}{ Larval } & \multirow[b]{2}{*}{ Var./mean } & \multicolumn{2}{|c|}{ Negative binomial } \\
\hline Date & Year & & Mean* & Variance & & d.f. & $\chi^{2}$ \\
\hline 26 July & 1996 & Fargo & 3.1 & 12.3 & 4.0 & 11 & $23.91^{\dagger}$ \\
\hline 26 July & 1996 & Mapleton & 1.5 & 2.5 & 1.6 & 5 & 3.03 \\
\hline 31 July & 1996 & Prosper & 3.8 & 6.7 & 1.8 & 9 & 8.36 \\
\hline 31 July & 1996 & Prosper & 3.5 & 5.9 & 1.7 & 8 & 5.78 \\
\hline 26 July & 1996 & Prosper & 4.7 & 10.8 & 2.3 & 11 & 10.49 \\
\hline 31 July & 1996 & Prosper & 6.6 & 20.1 & 3.0 & 17 & 18.98 \\
\hline 31 July & 1996 & Prosper & 2.2 & 4.3 & 2.0 & 7 & 3.35 \\
\hline 22 July & 1997 & Litchville & 9.2 & 44.4 & 4.8 & 25 & 12.28 \\
\hline 22 July & 1997 & Litchville & 8.7 & 26.5 & 3.0 & 22 & $41.72^{\dagger}$ \\
\hline 22 July & 1997 & Litchville & 7.1 & 19.8 & 2.8 & 18 & 13.93 \\
\hline 23 July & 1997 & Alice & 4.0 & 6.7 & 1.7 & 10 & 6.88 \\
\hline 23 July & 1997 & Alice & 6.6 & 27.7 & 4.2 & 20 & 17.00 \\
\hline
\end{tabular}

* In 1996, $N$ for individual field means was 100. In 1997, $N$ for individual field means is 160 .

$\dagger$ Significant at the $5 \%$ level $(P<0.05)$.

from 2.96 to 4.03 . When numbers of larvae in the field center (3.35 per plant) were compared to larvae closer to the field margins (3.69 per plant), the difference was not significant $(F=0.89, P>0.34$, d.f. $=1,698)$.

For the period when sampling occurred, the most abundant larval stage per plant was second instars (2.0), next was third instars (0.9), followed by first instars (0.4) and fourth instars at (0.3 larvae per plant). This pattern was maintained regardless of location in the fields. Plant development ranged from the initial floral bud stage (R1) to the late bud stage just prior to anthesis (R4). The mean plant stage was R2.4. Total numbers of larvae declined with advancing plant stage.

One hundred observations were made in each field to test fitness of numbers of larvae per plant to Poisson and negative binomial distributions. In 1996, the ratio of variance per mean for frequency counts of larvae was greater than 1 (Table 1). Except for the Fargo field, computed chi square values for the negative binomial distribution did not differ significantly from the expected.

LARVAL DISTRIBUTION 1997: Larval populations on sunflower plants in the five commercial fields sampled were low ( 0.7 per plant) compared to 1996 (3.6 per plant). Within fields, mean densities of larvae per plant were significantly higher $100 \mathrm{~m}$ into the field $(0.84$ larvae/plant) than on the edge (0.68), $20 \mathrm{~m}(0.67)$, or $50 \mathrm{~m}(0.66)$ into the fields $(F=6.78$, $P=0.0002$, d.f. $=3,789)$. There were significantly fewer larvae along the east $(0.50)$ side of the field compared to the north (0.82), south (0.79), or west $(0.74)$ sides of the fields sampled $(F=18.74, P<0.01$, d.f. $=3,789)$. For the five fields sampled, plants were in the early bud stage (R1-3). As in 1996, except for one field, the 1997 populations fit the negative binomial model (Table 1).

PARASITOID DISTRIBUTION 1997: Dissections of larvae from the 1997 fields revealed no difference in rates of larval parasitism by $M$. macellus among any of the four locations sampled or at the different distances into the fields. The mean rates were low, ranging from 1.4 to 5.1 parasitoids per 50 larvae.

PARASITOID DISTRIBUTION 1998: Larvae were again dissected in 1998 to determine percent parasitism by $M$. macellus. The overall numbers of parasitoids per 50 larvae were higher in 
Table 2. Dispersion parameters of the sunflower beetle larval parasitoid, Myiopharus macellus, in hybrid sunflower fields in North Dakota, 1997, 1998.

\begin{tabular}{|c|c|c|c|c|c|c|c|c|c|}
\hline \multicolumn{2}{|c|}{ Sampling } & \multirow{2}{*}{$\begin{array}{c}\text { Field } \\
\text { location }\end{array}$} & \multicolumn{2}{|c|}{ Parasitoid } & \multirow[b]{2}{*}{ Var./mean } & \multicolumn{2}{|c|}{ Poisson } & \multicolumn{2}{|c|}{ Negative binomial } \\
\hline Date & Year & & Mean* & Variance & & d.f. & $\chi^{2}$ & d.f. & $\chi^{2}$ \\
\hline 22 July & 1997 & Litchville & 2.2 & 3.6 & 1.6 & 2 & 2.34 & 3 & 2.25 \\
\hline 22 July & 1997 & Litchville & 1.6 & 1.3 & 0.8 & 1 & 0.10 & 一 & - \\
\hline 22 July & 1997 & Litchville & 1.4 & 1.6 & 1.1 & 1 & 0.06 & 1 & 0.64 \\
\hline 23 July & 1997 & Alice & 5.1 & 9.4 & 1.8 & 5 & $9.21^{\dagger}$ & 7 & 11.31 \\
\hline 23 July & 1997 & Alice & 2.9 & 7.8 & 2.7 & 3 & $7.49^{\dagger}$ & 5 & 4.10 \\
\hline 21 July & 1998 & Alice & 4.7 & 5.6 & 1.2 & 5 & 2.09 & 6 & 4.00 \\
\hline 21 July & 1998 & Chaffee & 7.3 & 14.3 & 2.0 & 7 & $13.17^{\dagger}$ & 10 & 7.48 \\
\hline 23 July & 1998 & Litchville & 3.4 & 4.8 & 1.4 & 3 & 0.56 & 5 & 2.33 \\
\hline 23 July & 1998 & Litchville & 3.6 & 2.9 & 0.8 & 3 & 0.75 & 一 & - \\
\hline 23 July & 1998 & Enderlin & 3.6 & 7.6 & 2.1 & 3 & 6.07 & 5 & 2.26 \\
\hline
\end{tabular}

* Parasitoid larvae per 50 sunflower beetle larvae. $N$ for field means was 16 .

$\dagger$ Significant at the $10 \%$ level $(P<0.10)$.

1998 (4.5) compared to 1997 (2.6). As in 1997, direction did not affect parasitism rates. However, unlike 1997, parasitism per 50 larvae was significantly reduced $(F=3.33, P=$ 0.0245 , d.f. $=3,69)$ on the field edges (3.3) compared to rates at $20 \mathrm{~m} \mathrm{(5.7)} \mathrm{and} 60 \mathrm{~m}(4.9)$ into the fields. Field edge rates did not differ from rates at $40 \mathrm{~m}$ (4.2). In 1997, parasitism was highest on the field margins. Parasitoid distributions in individual fields did not consistently fit either the Poisson or negative binomial models (Table 2).

\section{Discussion}

In both 1996 and 1997, populations of sunflower beetle larvae were significantly lower on one field side compared to the other sides. However, the location of field sides with the highest and lowest population levels were not consistent between years. The reason for the difference is not clear but may be influenced by immigration from previous years sunflower fields. None of the populations were at economic levels and only one of the fields had been treated with insecticide early in the season. In 1997, population levels varied with distance into the field. It appears that to avoid error in estimates of population size, sampling needs to include multiple sides and distances into fields to accurately determine the population density of sunflower beetles.

The variance-to-mean ratio of numbers of sunflower beetle larvae at sampling sites was consistently greater than one. According to Southwood (1978), sample variance-to-mean ratios greater than one are indicative of aggregated or negative binomial distributions. The data, with the exception of one field each year, fit the negative binomial distribution. Like many insects, the sunflower beetle appears to usually have a clumped or aggregated distribution in commercial sunflower fields. Since larvae are probably not moving from plant to plant, their distributions reflect female choice in oviposition site. Little is known about ovipositional host preference by sunflower beetle but as numbers of larvae declined with plant stage, it may be that young plants are preferred to older plants for oviposition.

PARASITOID DISTRIBUTION: Parasitoid population levels were relatively uniform across the field sites sampled. This shows that the adult parasitoid is capable of effectively searching throughout commercial sunflower fields. However, the parasitism rates were considerably lower in 1977 and 1978 compared to the greater than 50\% rates reported by Charlet 
(1992). The reason for the low parasitism rates in our study is not accounted for by insecticidal treatment since only one field out of the 12 sampled was treated with an insecticide. However, the general history of insecticide use over years may have suppressed parasitoid populations in the area. Another possible factor is that Charlet (1992) was reporting parasitism rates in 0.5 ha plots instead of larger, commercial fields as we evaluated. Recently, Charlet (2003) compared parasitism in native and cultivated sunflowers and found parasitism rates by M. macellus of 4 to $5 \%$ in multiple commercial fields sampled in 1996 in North Dakota and Minnesota.

Our data describing the pattern of M. macellus distribution is less clear than for the sunflower beetle larvae. Parasitism rates were low making fit to the models difficult. However, in most cases the ratio of the variance per mean exceeded one and the $\chi^{2}$ model of a negative binomial distribution was supported at the $10 \%$ probability level. This indicates that M. macellus tends toward an aggregated distribution. This is likely if parasitoid searching success is increased in clumps of higher density sunflower beetle larvae. Better estimates of parasitoid distribution could be obtained when parasitism rates are higher and by sampling fields more comprehensively.

The sunflower beetle is a frequent target of insecticide application in the northern Plains states of North Dakota, South Dakota, and Minnesota. Management plans for the sunflower beetle include sampling of populations and/or using visual estimates of defoliation. The data gathered in this study will be useful in developing more efficient sampling protocols.

\section{Acknowledgment}

We thank C. Peng and W. Schmidt, North Dakota State University and T. Gross, USDA, ARS, Fargo, ND, for assistance with field and laboratory studies.

\section{Literature Cited}

Brisley, H. R. 1925. Notes on the Chrysomelidae (Coleoptera) of Arizona. Transactions of the American Entomological Society 51:167-182.

Charlet, L. D. 1991. Overwintering survival and emergence pattern for the sunflower beetle (Coleoptera: Chrysomelidae) in the northern Great Plains. Journal of Economic Entomology 84:132-135.

Charlet, L. D. 1992. Seasonal abundance and parasitism of the sunflower beetle (Coleoptera: Chrysomelidae) on cultivated sunflower in the northern Great Plains. Journal of Economic Entomology 85:766-771.

Charlet, L. D. 2003. Incidence of sunflower beetle (Coleoptera: Chrysomelidae) and parasitism of its larvae by Myiopharus macellus (Reinhard) (Diptera: Tachinidae) in native sunflowers in North Dakota and Minnesota. Journal of the Kansas Entomological Society 76:436-441.

Charlet, L. D., G. J. Brewer, and B. Franzmann. 1997. Insect pests. In A. A. Schneiter (ed.). Sunflower Technology and Production, pp. 183-261. Agronomy Series 35. American Society of Agronomy, Madison, Wisconsin, xv $+834 \mathrm{pp}$.

Knodel, J. J., L. D. Charlet, and P. A. Glogoza. 2000. Biology and Pest Management of the Sunflower Beetle in North Dakota. North Dakota State University Extension Bulletin E-824. 8 pp.

Pedigo, L. P., and M. R. Zeiss. 1996. Analyses in Insect Ecology and Management, 1st ed. Iowa State University Press. xi +168 pp.

Rogers, C. E. 1977. Bionomics of the sunflower beetle (Coleoptera: Chrysomelidae). Environmental Entomology 6:466-468.

SAS Institute. 1985. SAS User's Guide: Statistics, Version 5. Cary, North Carolina.

Schneiter, A. A., and J. F. Miller. 1981. Description of sunflower growth stages. Crop Science 21:901-903.

Southwood, T. R. E. 1978. Ecological Methods, 2nd ed. Chapman and Hall, London. xxiv + 524 pp.

Westdal, P. H. 1975. Insect pests of sunflowers. In J. T. Harapiak (ed.). Oilseed and Pulse Crops in Western Canada-A Symposium, pp. 479-495. Modern Press, Saskatoon, Saskatchewan, 703 pp. 